\title{
PLATAFORMA CONE MORSE, O IMPLANTE COM RESOLUÇÃO PROTÉTICA ESTÉTICA, COM OS TECIDOS PERI-IMPLANTARES
}

Morse cone platform, the implant with aesthetic proteic resolution, with the periimplant tissues

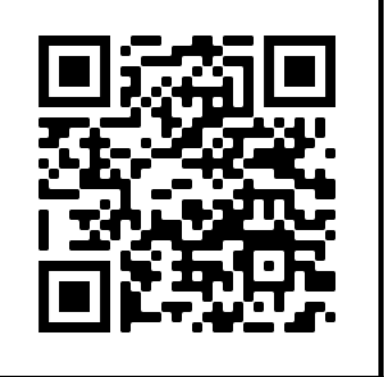

\section{Autores:}

\section{Bruno Pires Miranda}

Mestre em Odontologia - UFF Especialista em implantodontia - UFF

\section{Jessica Samile Silva Goveia}

Cirurgiã Dentista - Universidade Salgado de Oliveira

\section{Helba Pires Miranda}

Cirurgiã Dentista - Universidade Salgado de Oliveira

\section{Prof. Dr. Marcos da Veiga Kalil}

Professor Adjunto do Departamento de Odontoclínica - UFF

Doutor em Endodontia - UERJ Especialista em Implantodontia, Especialista em Periodontia, Especialista em Radiologia odontológica e Especialista em Gestão da Educação - UFF Mestre em Clínica Odontológica - UFF

Coordenador do Laboratório de Microbiologia Oral (LabMOral) da Faculdade de Odontologia UFF

\section{Endereço para correspondência:}

Bruno Pires Miranda

Rua Desembargador Lima Castro, 19 - sobrado - Fonseca, Niterói - RJ CEP: 24.120-350

Telefone: (21) 99826-0202

E-mail: brunopiresmiranda7@gmail.com

\section{RESUMO}

Os problemas decorrentes de perdas dentárias em áreas estéticas têm sido motivo de intensa dedicação científica e empenho clínico a fim de alcançar 
estabilidade mecânica e estética favoráveis. O advento dos implantes dentários-osseointegráveissupriu quesitos de suporte mecânico; no entanto, a remodelação óssea cervical ao redor de implantes com plataforma convencional pode comprometer significativamente a manutenção dos tecidos peri- implantares, gerando sérios agravos estéticos. Atualmente, o objetivo da instalação de implantes Cone Morse vai além de atender a uma tendência evolutiva em Implantodontia, proporcionando a manutenção das características teciduais peri-implantares e o favorecimento da confecção de próteses estéticas, direcionando todo o processo terapêutico a possibilitar perfil de emergência ideal e relacionamento natural e harmonioso com os tecidos circunjacentes. Logo, essa revisão bibliográfica tem o intuito de apresentar tais características, que conferem um alto índice de sucesso e de longevidade das peças protéticas, garantindo maior previsibilidade de manutenção das condições em reabilitações protéticas.

Palavras-chave: Plataforma Cone Morse, prótese dentária, implante.

Keyword: Morse Platform, dental proshesis, implant.

\section{INTRODUÇÃO}

Quando (Branemark, PI, et al, 1977) descreveram o processo de osseointegração para reabilitar pacientes totalmente edêntulos, não se cogitava a estética dessa reabilitação, visava-se, exclusivamente, a função. Com a evolução dos implantes, o grau de exigência dos pacientes aumentou e a reabilitação deixou de ser meramente funcional, tomando-se também, estética. O desafio diário do cirurgião-dentista buscando resultados voltados para a estética leva a novos parâmetros, onde a previsibilidade estética antenada aos novos anseios dos pacientes. Parâmetros que outrora atendiam a função, agora se utilizam de recursos como planejamento prévio da prótese, posicionamento tridimensional do implante, análise dos fatores de custo estético, enceramento diagnóstico, guia cirúrgico, manejo de tecidos periimplantares e, até mesmo, planejamento por sistemas computadorizados, como o CAD/CAM (BERNARDES SR, et al, 2009).

De acordo com Pereira, a previsibilidade de um tratamento provém de um planejamento criterioso e meticuloso, sendo que antes analisava-se onde era possível a colocação de implante, mas hoje avalia-se a melhor condição protética para estabelecer a melhor função e estética, atendendo, assim, a 
necessidade do paciente moderno. Esse estudo recebeu o nome de "planejamento reverso".

Segundo (GOMES MGN, et al, 1999), os resultados estéticos e funcionais fizeram com que a Odontologia Restauradora buscasse novos materiais e componentes que atendessem essa nova demanda. $O$ ponto fraco da osseointegração, que necessitava ser superado, era na interface implante/ conexão protética/ coroa artificial, a qual deveria proporcionar uma aparência mais natural, principalmente na região cervical, onde se encontra o maior desafio protético; isso além de alcançar a estética dos dentes vizinhos e dos tecidos de suporte. Logo, o mercado que apresentava conexões hexagonais, octogonais e triangulares, deu espaço às conexões cônicas internas.

A conexão cônica interna, que é amplamente conhecida como Cone Morse, tornou-se referência em estudos quando a resolução protética envolve estética. As características desse sistema englobam a diminuição da contaminação bacteriana, minimização de fendas na interface de conexão implante/pilar, melhor estabilidade antirrotacional e torque de soltura superior ao de apertos (COPPEDÉ AR, et al, 2009).

Para a manutenção das estruturas ósseas, é fundamental a sustentação dos tecidos peri-implantares e a estabilidade das conexões; logo, houve o desenvolvimento de alternativas protéticas, como os pilares Cone Morse, que atendem a diversos fatores estéticos que não eram possíveis com outras conexões, como contorno gengival natural e boas características de luminosidade da prótese (SILVA CR, et al, 2011).

Este trabalho pretende, por meio de uma revisão de literatura, esclarecer as características da interface protética do sistema Cone Morse e sua relação com resultados estéticos em reabilitações sobre implantes osseointegrados.

\section{REVISÃO DE LITERATURA}

\section{Conceito Cone Morse}

Stephen A. Morse desenvolveu um mecanismo de encaixe que gera retenção. Esse mecanismo era utilizado na indústria da manufatura de ferramentas mecânicas. O sistema foi criado pela necessidade de reter urna broca ou mandril em máquinas de corte, tal como furadeiras. O sistema funcionava pela ação de fricção de contato de urna interface "macho/ fêmea". Sua eficácia é 
aumentada pela pré-carga gerada nas superfícies friccionais, resultando em estabilidade. Dessa forma originou-se o termo Cone Morse na Implantodontia.

As conexões do tipo Cone Morse permitem a confecção de práreses com características mais próximas das naturais, principalmente em áreas que envolvem a estética. Isso ocorre por seu design interno preciso, que permite um íntimo contato das superfícies, gerando uma resistência mecânica similar a uma peça única com ausência de microgap, levando a uma maior capacidade de suportar forças horizontais, maior resistência mecânica e diminuição de pontos de tensãos.

O componente protético entra em contato com o implante Cone Morse por meio de sua interface, não existindo uma área de assentamento protético sobre a parte superior da região cervical do implante, por não apresentar plataforma protética. Esse fato possibilitou a idealização de componentes protéticos de mesmo desenho para todos os diâmetros de implante, diminuindo a variedade de componentes estocados no consultório odontológico. O orifício central é o mesmo em todos os diâmetros de implantes, exceto por raras exceções (SARTORI IM, et al, 2008).

A interface do implante Cone Morse não apresentava nenhum tipo de sistema antirrotacional. Porém, atualmente, foi inserido nessa superfície um encaixe, conhecido como index protético, sendo especialmente usado no caso de implantes unitários onde a inserção da prótese deve ser guiada para um encaixe estético perfeito. Os pilares indexados são do tipo parafuso passante, que mostra a posição da prótese em relação ao implante, não permitindo a modificação da inserção protética (SARTORI IM, et al, 2008).

A conexão Cone Morse cria uma interface fortemente estável devido ao íntimo contato das paredes desse componente com as superfícies internas do implante; logo, os parafusos desse sistema são menos solicitados. Diante disso, a plataforma cônica interna possui melhor estabilidade mecânica, quando comparada aos de junção hexagonal externa.

Os intermediários dos implantes Cone Morse não apresentam o parafuso e o componente em duas peças separadas, esses são sempre juntos, porém podem ser vistos em duas linhas: intermediário de peça única ou com parafuso passante. O parafuso da linha parafuso passante fica preso no componente, sem existir a possibilidade do profissional tirar o parafuso que fica alojado transpassando o intermediário (SARTORI IM, et al, 2008). 
Dentro dos sistemas Cone Morse, há os que se adaptam à parede cônica do pilar intermediário por meio do aperto das roscas de um parafuso, e os com encaixe somente pela conicidade, chamados de sistema Cone Morse puro ou friccional (SOARES MAD, et al, 2009).

Em áreas estéticas, os implantes Cone Morse devem ser instalados de 1 a $2 \mathrm{~mm}$ infraósseo para otimizar e facilitar a manutenção dos tecidos que circundam o terço cervical do implante dentário. Caso a quantidade de tecido gengival não seja suficiente, poderá ocorrer exposição de metal do sistema de retenção, exigindo componentes especiais ou a personalização do pilar protético para possibilitar reabilitações que não interfiram com a estética (SARTORI IM, et al,2008).

\section{Vatagens e Desvantagens}

Principais vantagens

» Ausência de microgaps na junção abutment/implante.

" Melhor transmissão de força abutment/implante.

» Melhor estabilidade abutment/implante.

"Retenção Morse (retenção friccional), distribuindo melhor as forças nas paredes internas do implante, diminuindo a reabsorção óssea cervical fisiológica.

" Conceito plataforma switching com pilares protéticos de menor diâmetro que o dos próprios implantes.

" Otimização imediata para casos estéticos, facilitando a estabilidade dos tecidos moles.

Principais desvantagens

»Custo.

» Dificuldade da técnica.

" Menor versatilidade de componentes protéticos (GEBRIM L, et al, 2005), (LIMA 1C, et al, 2008), (THOMÉ G, et al, 2011).

\section{Seleção do Pilar Protético}

Segundo Pereira, devemos observar alguns dados para selecionarmos 0 componente, tais como altura gengival e sua correspondência com o pilar de cicatrização que foi instalado. 
(MISCH CE 2008) definiu o transmucoso do pilar protético como o limite entre a parte destinada à coroa do pilar protético e a parte que está presa na parte interna do implante, ficando essa porção inteira dentro da gengiva. Para uma correta escolha de componentes, devemos seguir tês diretivas (SARTORI IM, et al , 2008):

a- Seleção do diâmetro da porção coronária do pilar protético. O diâmetro do intermediário pode ser de 3,3 e 4,5mm. A escolha deve basear-se no tamanho da coroa que será utilizada, sendo que a coroa de menor diâmetro normalmente é utilizada para dentes anteriores.

b- Seleção da altura do transmucoso. A escolha do pilar protético deverá observar a distância do osso e altura da gengiva em relação ao transmucoso do pilar protético. A altura do transmucoso dos intermediários retos varia de 0,8 a $5,5 \mathrm{~mm}$; já dos angulados, varia de 1,5 a $3,5 \mathrm{~mm}$. A escolha deve ser feita de acordo com a altura gengival presente, observando os seguintes requisitos:

" Osso: durante a seleção do componente protético, devemos realizar uma radiografia para avaliar a relação do término da prótese com a crista óssea. Essa distância deve ser de, no mínimo, $1 \mathrm{~mm}$, porém, valores de 2 a $3 \mathrm{~mm}$ são preferíveis quando existe essa possibilidade. Essa manobra visa a manutenção do tecido ósseo, em virtude de respeitar o espaço biológico peri-implantar, devido aos cuidados que devemos ter com a linha de cimentação.

" Gengiva: em próteses estéticas, o perfil de emergência deve estar subgengival, logo, o transmucoso do intermediário deve estar $2 \mathrm{~mm}$ abaixo do nível gengival. Como o formato interno é o mesmo, se a altura do transmucoso do cicatrizador tiver sido escolhida muito alta, o tecido gengival formado vai respeitar aquele desenho. Se a escolha do transmucoso não for compatível (for mais baixa), o intermediário exercerá muita pressão nos tecidos e o paciente relatará dor por compressão. Assim sendo, recomenda-se a escolha dos cicatrizadores no mesmo diâmetro do intermediário e na altura do tecido gengival. A escolha da altura do intermediário deverá ser compatível.

c- Seleção da altura da porção coronária do pilar protético A altura da porção coronária do pilar protético poderá ser de 4 e $6 \mathrm{~mm}$, de acordo com a altura interoclusal.

Para fazer a escolha, o profissional poderá utilizar kits de seleção desenvolvidos para esse fim, ou tentar tomar todas as referências para seu uso, observando os pilares de cicatrização que estão instalados. A empresa 
Neodent (Curitiba/PR) desenvolveu um medidor de altura Cone Morse, com o intuito de facilitar a determinação da altura do transmucoso. Essa chave milimetrada é conectada ao hexágono do implante localizado abaixo do sistema Morse, preservando as paredes desse sistema, para que sejam tocadas apenas peto componente protético no ato de sua instalação.

Os pilares protéticos também são conhecidos como intermediários, transmucosos ou abutment, de acordo com PEREIRA, et al. A maneira como o implante se reiadora com o componente protético denomina-se conexão protética (RODRIGUES DM, et al, 2007).

Para a seleção adequada do pilar protético, deve estar predefinido se a prótese é cimentada ou parafusada. Em reposições de dentes anteriores, deve-se, sempre, optar por próteses cimentadas, já que essas escondem o acesso do parafuso, podendo, assim, resolver casos de implantes com emergência não ideais. Permitem, também, a iocazação cirúrgica de implante mais relacionado ao longo eixo do elemento dentário, resultando em coroas de anatomias mais naturais. Apenas nos casos em que o fator reversi- bitidade for importante, as próteses parafusadas serão de eleição. Também devemos analisar se a prótese é unitária ou múltipla, espaço protético interoclusal (altura e largura), necessidade de correção de angulação ou paralelismo entre os componentes, quantidade (altura) e qualidade do tecido transmucoso e a distância do término da prótese (linha de cimento) a crista óssea peri-implantar (SARTORI IM, et al , 2008).

Com a crescente exigência estética pelo paciente, houve o desenvolvimento de novos componentes, visando tanto a maior resistência quanto a melhor estética. Surge no mercado uma ampla variedade na forma dos pilares, diferentes angulações, altura do transmucoso, formatos e materiais, proporcionando uma aparência agradável, tanto para a restauração como para o tecido peri- implantar. Porém, apesar da disponibilidade de vários tipos de conexões e pilares, um mau planejamento, principalmente para a região anterior, pode tornar inatingível a obtenção de boa estética.

\section{Munhão Universal}

Pode ser sólido ou com parafuso passante. O munhão universal sólido é um componente de peça única, indicado para próteses múltiplas e em implantes bem posicionados, facilitando a inserção da prótese, onde não haverá 
necessidade de adaptações no componente, tanto no sentido vertical quanto no cervical (SARTORI IM, et al, 2008).

O munhão universal de parafuso passante é indicado para próteses unitárias cimentadas. Sempre haverá a confecção de "núcleos" e uma infraestrutura protética que será adaptada a eles, podendo ser adaptado em casos de inclinações de implantes ou em relação ao contato cervical, onde se deseja personalizações de áreas proximais. O munhão universal é contraindicado em espaço interoctusal insuficiente e em posição tridimensional do implante insatisfatória. Pode ser preparado em laboratório.

Em situações que necessitam de grandes personalizações do pilar protético ou em casos em que o tecido mole da área a ser reabilitada apresenta diferentes alturas de papila, ou em situações em que a altura do tecido gengival na face vestibular exige um tamanho de transmucoso que não mostra uma boa opção de altura em relação ao nível ósseo interproximal, deve-se ubizar o munhão de parafuso passante, já que esse componente pode ser preparo em laboratório. Em contrapartida, casos onde há limitação do espaço interoctusal, sem a necessidade de modificação no término, a personalização pode ser feita diretamente em boca. Quando houver necessidade de angulação do componente, mas não há necessidade de preparo cervical, o munhão universal angulado pode se' escolhido e instalado diretamente em boca. Esse componente é oferecido em duas opções de diâmetro (3,3 e 4,5mm) e em duas opções de comprimento da parte coronária (4 ou $6 \mathrm{~mm}$ ).

A seleção dependerá do espaço interoclusal oferecido e da área de cimentação que se deseja. Os implantes angulados são disponíveis em $17^{\circ}$ e $30^{\circ}$ (SARTORI IM, et al, 2008).

\section{Munhão Anatômico}

É um pilar da mesma linha do munhão universal com parafuso passante, porém com quantidade maior de metal para idealização do preparo. As áreas expostas nas faces livres podem ser preparadas em laboratório, da mesma forma que os munhões de parafuso passante ou pelo próprio cirurgião-dentista. Há o munhão anatômico para repor incisivos centrais e outro específico para incisivos laterais. O munhão anatômico é indicado para próteses cimentadas unitárias, em áreas estéticas. São usados em casos em que se deseja a vestibularização da emergência da coroa, já que ele estende a área cervical para que o perfil de emergência possa ser facilitado. Tem como vantagens 
permitir adaptações da porção coronária, cervical e de contorno interno (SARTORI IM, et al, 2008).

\section{Munhão Personalizável Especial de 0,2mm}

O implante Cone Morse deve ficar infraósseo em áreas que englobam a estética; porém, às vezes, isso não ocorre, resultando na exposição do implante na cavidade bucal, impedindo a instalação de qualquer um desses intermediários devido à porção metálica, que ficaria aparente. Logo, indica-se, nessa situação, o munhão personalizável de $0,2 \mathrm{~mm}$. Também é utilizado em casos onde não há tecido gengival para esconder a porção cervical dos intermediários ou implantes com problemas no posicionamento que levam a emergências vestibularizadas dos parafusos. Indicado em casos especiais de prótese unitária cimentada, onde houve erros de indicação ou de instalação do implante (SARTORI IM, et al, 2008).

Esse componente foi desenvolvido para resolver complicações de casos complexos. O correto seria evitá-lo, por isso não está disponibilizado no catálogo da Neodent, para evitar banalização do produto e por levar a perda do benefício biológico da filosofia Cone Morse (PEREIRA JR).

\section{Minipilar Cônico}

Conhecido como minipilar Cone Morse, MirusCone, Micruscone, Miniabutment, Multi-unit, Micro-unit ou UMA, é uma opção para as próteses múltiplas parafusadas. É oferecido de acordo com as opções de transmucosos e angulações já comentadas. O minipilar cônico é contraindicado para próteses unitárias e/ou cimentadas, espaço interoclusal insuficiente e posição tridimensional do implante insatisfatória (SARTORI IM, et al, 2008) (COELHO $A B$, et al, 2013).

O minipilar cônico reto é urna opção de componente para implantes em próteses múltiplas, já que não há componente antirrotacional nos cilindros protéticos, pois essa característica antirrotacional pode dificultar o assentamento da prótese por falta de paralelismo entre os implantes. Tem que haver um espaço mínimo interoclusal de $4,4 \mathrm{~mm}$ a partir do nível da mucosa (PEREIRA JR) (Catálogo de produtos Neodent, 2013). 
Em casos de implantes inclinados no sentido vestibulopalatino ou mesiodistal em próteses múltiplas, é indicado o minipilar cônico angulado para dar o correto eixo de inserção para a prótese ou para resolver problemas estéticos de emergências vestibularizadas de implantes; porém, não há modificação do tipo de incidência de carga nos implantes inclinados. Esse componente poderá ser encontrado com angulações entre $17^{\circ}$ e $30^{\circ}$. Para esse tipo de angulação, é necessário que haja tecido gengival suficiente para esconder as cintas dos componentes angulados, para que a estética não fique prejudicada. Nos casos de minipilar cônico, o parafuso vai estar unido ao intermediário (parafuso fixo), já para o minipilar angulado o parafuso vai ser passante (PEREIRA JR).

A empresa Neodent desenvolveu um pilar para casos com espaço interoclusal reduzido, conhecido como micropilar Cone Morse. É indicado para prótese múltipla parafusada com espaço mínimo interoclusal de $3,5 \mathrm{~mm}$ a partir do nível da mucosa, e para implantes próximos entre si (Catálogo de produtos da Neodent, 2013).

\section{CONSIDERAÇÕES ESTÉTICAS RELACIONADAS AOS ASPECTOS TECIDUAIS}

As vantagens do sistema Cone Morse, quando se trata de regiões estéticas, são imensas, já que, normalmente, nessas situações ternos que esconder qualquer linha divisória entre o intermediário protético e o implante. O sistema Cone Morse diminuiu as distâncias mínimas necessárias entre implantes e entre dentes e implantes, facilitando a manutenção das papilas, já que a distância correta entre implantes ou entre implante e dente natural também é essencial para um resultado estético favorável (BIANCHINI M, 2013).

A estética gengival ao redor dos dentes é baseada em uma dimensão vertical constante dos tecidos periodontais saudáveis, conhecida como distância biológica. Elas são responsáveis pela proteção do tecido ósseo e gengival e atuam como uma importante barreira entre o meio interno e o meio externo do organismo. Ao redor dos implantes dentários, têm-se essas mesmas estruturas de proteção. No tecido peri-implantar, é possível uma regeneração epitelial e conjuntiva, com a formação do sulco gengival, epitélio juncional e fibras da inserção conjuntiva, ou seja, as dimensões das distâncias biológicas nos implantes se assemelham às distâncias biológicas ao redor dos dentes naturais. 
No entanto, quando se avalia radiograficamente os diferentes sistemas de implantes, os parâmetros peri- implantares mostram diferença. Logo, a dimensão da distância biológica parece diferir entre os sistemas de implantes, devido à presença ou não de reabsorções peri-implantares, pois a distância biológica é dependente da localização da crista óssea alveolar. No sistema Cone Morse, há uma preservação de tecido ósseo, mesmo após a instalação do pilar protético.

A avaliação criteriosa do tipo de recobrimento gengival, a espessura (a manutenção do nível gengival pode não estar garantida em casos de gengiva com biótipo fino) e a quantidade de tecido mole disponível são fatores decisivos no resultado estético. Também há outro fator de suma importância para termos sucesso por meio da avaliação clínica e radiográfica das estruturas duras do sítio implantar e adjacências, no que diz respeito à altura e largura óssea (SOARES M, 2013).

A ausência de inflamação peri- implantar e a perda óssea bastante reduzida são as grandes responsáveis pela manutenção da estética em longo prazo. Logo, a conexão tipo Cone Morse representa a possibilidade de otimização de tais problemas, já que evita o acúmulo de biofilme bacteriano e, consequentemente, a saucerização e inflamação gengival (MISCH CE, 2008).

A perda da papila interproximal está diretamente relacionada à reabsorção óssea ao redor dos implantes e intermediários. Essa perda pode ser causada por trauma cirúrgico, sobrecarga, peri-implantite, anatomia da região cervical, características da superfície dos implantes, adequação biológica, presença de um microgap e pelo tipo de ligação entre o implante e a prótese, podendo acarretar problemas na estética e fonética, além da possibilidade de impacção alimentar (TARNOW DP, 2000).

Em casos em que não há espessura suficiente de mucosa ceratinizada, indicase cirurgia plástica peri-implantar, que vai ser essencial para a estética e para a realização da higiene bucal. Se houver associação de perda parcial de tecidos moles com linha de sorriso alta, a situação torna-se extremamente desfavorável e difícil, exigindo etapas de reconstituição de tecido mole e duro remanescentes. 


\section{CONCLUSÃO}

O sistema Cone Morse apresenta vantagens protéticas significativas quando comparado aos hexágonos, principalmente em elementos unitários anteriores, onde a longevidade da estética gengival é de suma importância, além de apresentar qualidades clínicas, biológicas e biomecânicas superiores. Logo, conclui-se que a plataforma Cone Morse apresenta características primordiais para um alto índice de sucesso e longevidade das peças protéticas, e uma maior previsibilidade de manutenção das condições peri-implantares em reabilitações de dentes anteriores.

\section{REFERÊNCIAS BIBLIOGRÁFICAS}

1. BRANEMARK Pi, HANSSON 130, ADELI R, BREINE U, LINDATROM J. HALLÉN 0. Osseointegrated implants in the treatment of the edentulous jaw. Experiente from a 10- year period. Scand J Plast Reconstr Surg Supl. 1977; 16:1-132.

2. BERNARDES SR, HERMAN C, ROMANINI ES, SARTORI AM. Seria possikilel evitar a perda óssea periimplantar? Revisão crítica com apresentação de um caso clínico. J ILAPEO. 2009; 3(2):83.

3. PEREIRA JR. Prótese sobre implante. São Paulo: Artes Médicas; Gomes MGN, Lima JHC, Schnetzier Neto A, Soares MDFS. Pró^tese sobre implantes: cimentada versus aparafusada. Rev BrasImplant. 1999; 5-8.

4. COPPEDÉ AR, BERSANI E, MATTOS MG, RODRIGUES RC, SARTORI IA, RIBEIRO RF. Fracture resistance of the implant-abutment connection in implants with internai hex and interna] conicai connections under oblidue compressivo an in vitro study. Int J Prosthodont. 2009; 22(3):283-6.

5. SILVA CR, GENNARI Filho H, GAIATO MC. Perda óssea em prótese sobre implante: revisão de literatura. Rev Odontol Araçatuba. 2011; 32(1):32-6.

6. SARTORI IM, BERNARDAS SR, MOLINARI A, HERMANN C, THOMÉ G. Intermediários para implantes Cone Morsa: seleção e utilização. J Ilapeo. 2008; 96-104. 
7. SOARES MAD, CIUCCIO RL, JACOMINI Filho A, LENHARO A, LUIZ NE. Implantes com conexão cônica interna. GEPROS. 2009; 4(2):13950 .

8. GEBRIM L. Design dos implantes osseointegrados. ImplantNews. 2005; 2(6):578-9.

9. CAUDURO PS, CAUDURO ME, SELISTRE R, OLIVEIRA RE, CAUDURO DE. Implantes Cone Morse e provisórios imediatos em área estética: 4 anos de acompanhamento. J ILAPEO. 2011; 5(3):84-8.

10.TANG CS, NAYLOR AE. Single-unit implants versus conventional treatments for compromised teeth: a brief review of the evidence. J Dent Educ. 2005; 69(4):414-8.

11. LIMA 1C. Cone morse: uma alternativa nas reabilitações sobre implantes. J Odonto Nordeste. 2008; 1(45):4-5.

12. THOMÉ G, GOLIN AL, CASTRO CG, SALATTI RC, VAIGAS L, BERNARDES SR. Considerações mecânicas e a importância do uso de implantes Cone Morse pra o sucesso em implantodontia. J ILAPEO. $2011 ; 5(4): 126-30$.

13. MISCH CE. Implantes dentais contemporâneos. 3a ed. Rio de Janeiro: Mosby Elsevier; 2008.

14. RODRIGUES DM. Manual de prótese sobre implante. São Paulo: Artes Médicas; 2007.

15. COELHO AB, TELLES D. Intermediários e componentes protéticos, In: Prótese sobre implantes. Cap. 3. [Acesso: 12 abr 2013]. Disponível em: http://www.google.com.br/ url?sa=t\&rct=j\&q=\&esrc.s\&source=web\&cd = 18,ved=0CDEQFjAA8curlttp $\% 3 A \% 2 F \% 2 F \quad$ www,cargairnediata.com.br \%2Findex.php\%3Foption\%3Dcom_cman\%26task\%3Ddoc_download \%26gid\%3D94\%26Itemid\%3-D1328,ei $=$ hZ041JoCGNoTu9ATp61HQBA\&usg =AFC)jCN F4Zrn3jJ-1 VpJ8]UN29WZipkMywHA.

16. Catálogo de produtos Neodent - Excelência e inovação. 1, ed. Curitiba: Neodent; 2013. 
17. BIANCHINI M. Cone morse em regiões estéticas: ainda a melhor solução. [Acesso: 16 jul 2013]. Disponível em: http://www.inpn. com.br/materia.asp.

18.SOARES M. Otimização estética com implantes em região maxilar anterior. [Acesso: 16 jul 2013]. Disponível em: http://monografias.brasilescola.com/medicina/otimizacao- estetica-com-implan-tesregiao-maxilar-anterior.

19. TARNOW DP. The effect of inter-implant distante on the height of interimplant bone crest. J Periodontol. 2000; 71(4):546-9. 